\title{
The golden reflections pottery in the historic town of san vicente, Buenos Aires, Argentina
}

\begin{abstract}
This article presents the exceptional finding of a type of ceramic that is very poorly represented in our country. It is a ceramics fragment found on the surface of the SV1 locus, located in the Old Town of San Vicente, Department of San Vicente, in the province of Buenos Aires, Argentine Republic. Its technology dates back at least to the fifteenth century although, according to historical analysis, it's macroscopic and archaeometric characterization, it is very likely that this fragment was produced in Spain during the s. XVIII, epoch in which the historic town of San Vicente is defined as such. The latter is deduced from the historical documentation of the ancient town of San Vicente and its close economic link with the city of Buenos Aires, access road for all types of goods from Europe. The analysis of this fragment allows us to suppose that the original piece to which it belonged could be a ceramic piece of holy water or a religious plate since most of the pieces made with this technology for that time would have been of religious-ornamental use, both in the entrances or oratories of domestic sites characteristic of the time, as in the old churches, such as the one located in the historical cemetery of San Vicente.
\end{abstract}

Keywords: golden reflections pottery, san Vicente, buenos aires, república argentina, century XVIII
Volume 3 Issue 6 - 2018

\author{
López Mariel Alejandra \\ Faculty, Department of Philosophy and Letters, Institute of \\ Archaeology, Buenos Aires' University, Argentina
}

\begin{abstract}
Correspondence: Mariel Alejandra López, Faculty, Department of Philosophy and Letters, Institute of Archaeology, Buenos Aires' University, Argentina, Tel (54II) 5287 2632,

Email marialarqueologia@yahoo.com.ar
\end{abstract}

Received: August 02, 2018 | Published: November 13, 2018

\section{Introduction}

The framework project of the investigations in the province of Buenos Aires deals with the territory of the Party of San Vicente as part of the first frontier of the city of Buenos Aires at the time of the Spanish conquest in the Rio de la Plata region (Figure 1). Who ordered it to be part of the memories and plans acquired was the the Excmo. Mr. Marqués de Loreto, Viceroy, Governor and Captain General of these provinces of the Río de la Plata". ${ }^{1}$ Geographically, this microregion of studies is part of what some authors ${ }^{2,3}$ have called "the Buenosairean regional area" that integrates, in turn, the geographical region of the "undulating pampas", configuring a plateau with many hills that do not exceed 100 meters above sea level and that generally vary between 10 and 35 meters in the current conurban zone.

This pampa is crossed by the rivers and tributary streams of Paraná and del Plata forming alluvial valleys so that, topographically, they alternate hills and bathed, watery and salty, since they conserve the sedimentary remains left by marine ingressions of more than 10,000 years ago. ${ }^{4}$ The regional historical investigations explain in a quite general way the form that was being constructed the territory that at the moment constitutes the Party of San Vicente in the province of Buenos Aires from what at the time of the first distribution of lands carried out by Garay in the 16th century it was called the Pago de la Magdalena, a large extension area that extended from the city of Buenos Aires to the Río Salado to the south and from the Río de la Plata to Monte to the west. ${ }^{5}$ Indeed, unlike other towns or cities, the most accurate origin of this town is, not a supposed reduction that speculatively would have settled in the town next to a lagoon (Laguna de la Reducción, supposedly that of San Vicente or Laguna del Ojo) but, a small church of a primarily family nature, as it was hoisted by one of the members of the Pessoa family, the church of San Vicente Ferrer.

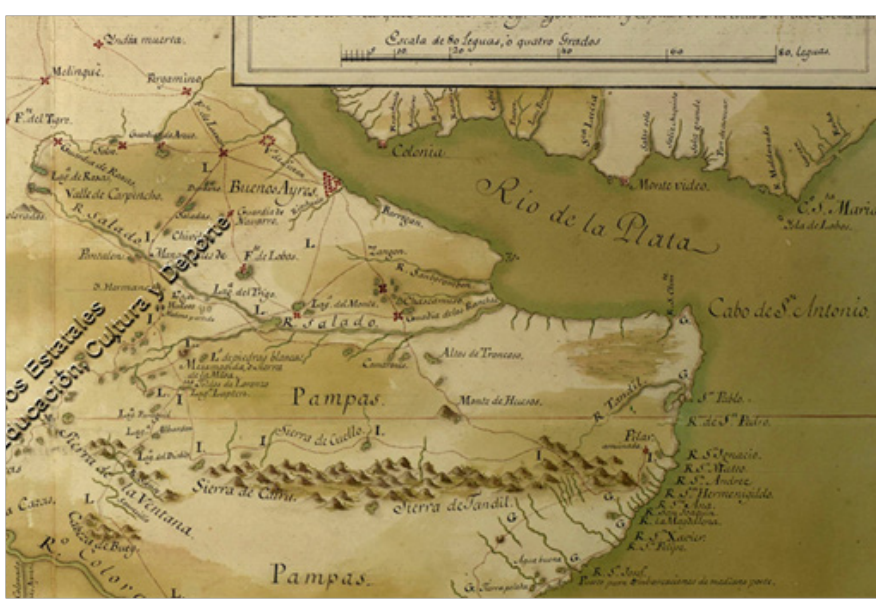

Figure I Sector of the "Geographic map that includes all the modern discoveries of the Patagonian Coast and its ports, from the Río de la Plata to the port of Río Gallegos, next to Cabo de las Vírgenes: the uncovered portion of the Río Negro and roads for the Campaign of Buenos Aires. The qual commanded to form by the memories and acquired plans, the Excmo. Mr. Marqués de Loreto,Viceroy, Governor and Captain General of these provinces of the Río de la Plata".

In fact, around it and around 1780, according to the various types of documents that are still preserved in the Historical Archive of San Vicente, it is that the old town or historic town of the San Vicente Party was formed; party that at that time also included the towns of Campana, Ranchos, Lobos and Monte, among the main ones that can be seen in Figure 1 and those that, in turn, subsequently were broken down into others. ${ }^{6}$ On this type of origin, around a church, other historical investigations of the region are also inclined. ${ }^{7,8}$ On the other hand, through documentation we have been able to corroborate 
that, from 1785, when the Cabildo of Buenos Aires assigned him the first Mayor of the Brotherhood, San Vicente began a course as an autonomous jurisdiction that culminated in 1801, when Saint Vincent appears as party and in 1822, when he was appointed his first Justice of the Peace, Pedro Pablo Udaquiola (Official Registry of the Province of Buenos Aires 1821-1822 LII, D266: 31). ${ }^{9}$

Among the archaeological objectives of the project that frames this investigation in San Vicente, is the study of the material culture that formed part of the daily life as well as the activities related to the ritual and festive of the first settlers of this town. In this sense, the finding of rare ceramic materials in archaeological sites in our country, such as golden reflections pottery, is not only an opportunity to advance understanding of the way of life of the place but, and more specifically, an opportunity to advance in its technological characterization.

\section{The historic town of san vicente and its strategic location en the Buenos Aires suburbs}

As can be seen in Figure 2, where San Vicente is marked with a red arrow as a locality very close to the ports of Buenos Aires (Argentina) and Colonia (Uruguay), cities marked with blue arrows, this historic town was strategically located in the vicinity of Buenos Aires, on the commercial route to the south of the country. In this sense, it is understood the double residence (San Vicente-Buenos Aires) on the part of its inhabitants, the merchants of the time, especially those who were dedicated to the exploitation of coipos, characteristic animal of the lagoon environment, and to the commerce of various types of goods. This double residence, as well as the intense trade between both localities, distant only about 55kilometers, can be observed in several documents consulted in the Archive of San Vicente and in many historical research works in the micro region (Figure 2). ${ }^{10-12}$ Although we have not yet found all the detailed records of the type of objects that arrived in San Vicente during the 18th century, we know from the Customs Act of 1862 that it was already a common and regulated practice to enter ceramic objects of European origin and predominantly in the form of tableware, to the port of the City of Buenos Aires.

In this sense, the golden reflections pottery presented in this work is interesting not only for its rarity in the archaeological records of our country, but also for the context of the historic town of San Vicente, whose first settlers of European origin were predominantly the English and then the Italians (according to the data that we are currently processing). Nevertheless, the presence of few similar fragments among the materials excavated in the City of Santa Fe la Vieja and in the Convent of Santa Catalina de Siena in the City of Buenos Aires, ${ }^{13}$ makes this type of ceramic materials an interesting challenge to deepen in its technological characterization, as well as in relation to its possible uses.

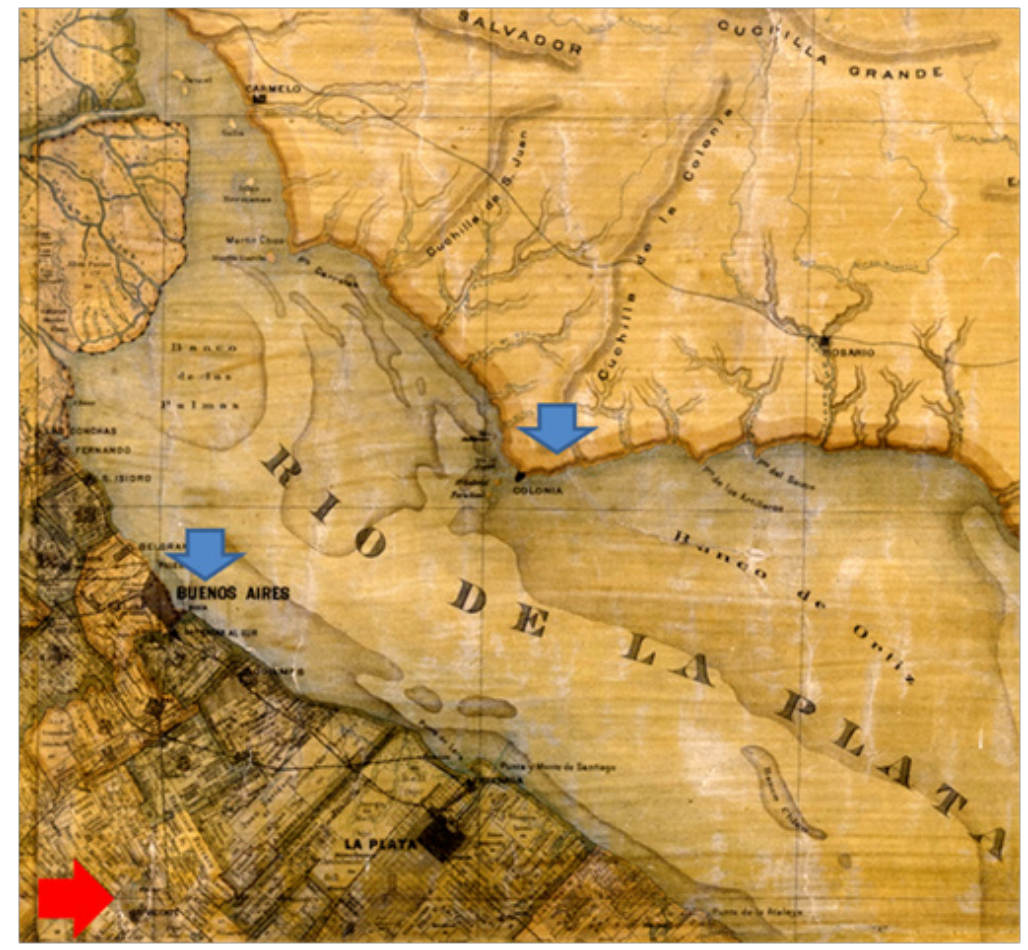

Figure 2 Sector of a map with the La Plata River Basin. In it you can see the settlement of San Vicente around the homonymous lake and the proximity of the cities of Buenos Aires (Argentina) and Colonia (Uruguay). BNA 1890.

\section{The golden reflections pottery}

The golden reflections pottery found on the surface of locus 1 (SV1) within the old town of San Vicente (Figure 3), whose identification and analysis we present in this work, constitute, as we have said, a type scarcely represented in Argentine Archaeology. In fact, the only allusion to this type is that of Schávelzon. In this sense, although the sample constitutes a single fragment, it is an interesting finding to characterize its type, to study its technology or mode of production with more advanced techniques and its possible functions or uses. In 
this last sense it is important to know its context of discovery. SV1 is a plot in front of the historical cemetery that, according to the study of the surveying planimetry carried out by the Agricultural Engineer Salas, at the beginning of the 19th century it was still municipal. In fact, the only indications of a very late occupation of this plot are the data provided by neighbours regarding a very humble house from the middle of the s. XX. The archaeological tasks carried out there consisted in the collection of the concentrations of objects in surface in its totality and the excavation of two stratigraphic soundings in relation to the foundation in sight of the aforementioned house. One made inside the residential structure and another outside, at the bottom of the land and next to the installation of a bath from the same period. The materials excavated inside the housing structure confirmed the mid 20th century date of the same, but not those found on the surface and whose origin is estimated to be the garbage produced by the periodic flooding of the lagoon that is attached to the cemetery. Floods on the other hand, are observable in the profile of the formation of the residential site before and after the foundation or pavement thereof.

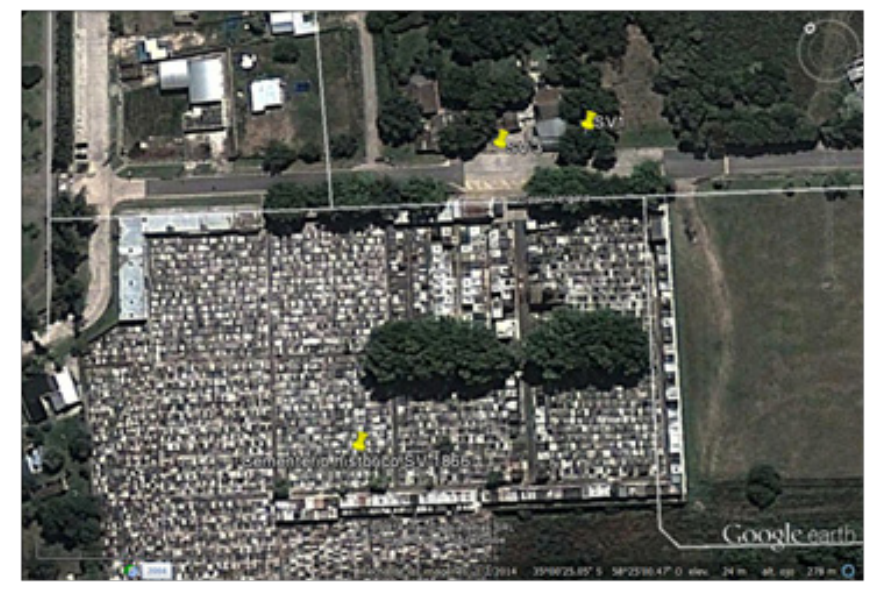

Figure 3 In the foreground you can see the historical cemetery of San Vicente, which was established as such in 1866 and still in use. In front of it locus SVI and SV3 are observed.

Figure 3 in the foreground you can see the Historical Cemetery of San Vicente, which was established as such in 1866 and still in use. In front of it locus SV1 and SV3 are observed. The interesting thing about these overflows, that towards the middle of the s. XIX caused the transfer of the old town and most of its inhabitants to the current location about ten blocks away, is that the northern sector of the lagoon still continues to overflow; even in spite of the levelling works carried out at different times. On the other hand, it is interesting to add to these data the stories of people over 70 years who remember that many times they saw, as children, floating cemetery materials in the adjacent lagoon due, among other factors, that at that time neighbours remember that there was a door on the wall that separates the cemetery from the lagoon where the "garbage" of the cemetery was thrown.

Finally, although the cemetery is conformed like Historical Cemetery towards 1866 , in agreement with the history of the formation of the old town or old town of San Vicente around a church whose location, in theory, would coincide with the one that at the moment can be seen at the entrance of this cemetery, it is interesting to say that the same types of overflows and "cleaning" work of the cemetery may have been carried out during the previous century, explaining in this way the presence of materials earlier than the nineteenth century. In fact, the accumulation and cleaning processes in the plots in front of the historical cemetery seem to be routine. Thus, while the SV1 site was excavated, we were able to photograph the historical "garbage" of the accumulated cemetery in the SV3 site which, after the cleaning done by the owners of said accumulated elements, was cleared and is currently in the process of being excavated.

\section{Brief history of golden reflections pottery}

This type of ceramic, also known as gilts or ceramics with metallic reflections or with a golden reflection or with a Hispano-Arabic reflection, has a type of decoration with iridescent effects produced by the metallic oxides applied in a third firing, that is, on a enamel already cooked. The decoration is produced fundamentally with copper and silver pigments. The result is a varnish of copper or gold metallic glitter. This technology is used since the Middle Ages and requires 3 firings: the first to cook the ceramic, the second for glazing and the third to achieve the golden reflections, ${ }^{14}$ which is why it is also called three-layer ceramic. The history of this type of ceramic technology would begin in Muslim Mesopotamia, then to North Africa and, finally, in the Iberian Peninsula (Spanish Levante). In this last locality it would have been introduced by the moriscos, who were distributed preferably in Manises, Paterna and Muel (Valencia). Although towards 1609 the moriscos were expelled from the peninsula, and with it this type of technology would be lost in part, as well as its secret formulas, in the middle of s. XVII, Teruel, Catalonia, Toledo and Talavera de la Reina or Seville were subsidiary foci of valencian tiles whose motives and techniques imitated. Nevertheless, and in spite of the attempts of imitation of the old Hispanic Moorish procedures, it would be necessary to wait for the s. XVIII so that the Spanish Levante recovered the wealth and hegemony in the world of the Spanish polychrome earthenware, with which it would have been the first factory to develop new techniques, the Real Fábrica de Alcora. Although, around 1780, labour problems forced many potters from Alcores to move to Manises, where, a century and a half later, there were some 80 factories in operation with about 1,000 workers, $30 \%$ of them women. ${ }^{15}$

Since then it is known that the entire process of its manufacture involved, even to the present, the following stages. First, and once the clay is extracted, basically composed of silica (SI) and aluminum (Al) and purified by drying it in the sun to avoid future cracks, the ceramic piece that is introduced to the oven for its first firing would be produced. Once the ceramic was obtained, the glaze consisting of a white varnish based on Lead $(\mathrm{Pb})$ and Tin $(\mathrm{Sn})$, as well as part of the decoration in Cobalt blue (Co), would then be applied. After this first covering of enamel, the piece would then pass to the second firing reaching approximately $990^{\circ} \mathrm{C}$. After that, and once the piece were cooled, it would be browned with a mixture of Copper Sulfides $\left(\mathrm{CuS}_{2}\right)$ and Silver $\left(\mathrm{AgS}_{2}\right)$ for which they would mix these minerals with Sulfur (S). All these pigmentary compositions would dissolve, likewise, in vinegar and they would be applied with a brush. Finally, the piece would be entered at the third firing, at an initial temperature of $650^{\circ}$, then down to $550^{\circ}$, in a reducing atmosphere..$^{16}$ In this way it can be said that although it is a technology that was changing in morphology and decoration, throughout time and space, it was preserved in its basic principles. Thus, the golden reflections pottery have constituted, from its beginnings in the middle ages until 8 centuries later (20th century), one of the most important advances as far as ceramic technology is concerned, since this type of surface finish it can be defined as a thin layer of metallic copper and silver nanocrystals (occasionally copper oxide) embedded in a glassy matrix 
where, in turn, they exchange with potassium and sodium. In this way, the authors speak of a nanostructured layer, whose optical properties make us see it with a metallic aspect. ${ }^{17}$

\section{Theoretical-methodological framework}

Even when dealing with historical materials, given the complexity of ceramic technology, the analytical perspective must be broad and integrative in order to overcome the basic morphological and decorative aspects with which it is usually characterized in a preliminary manner. We propose that even if at first glance this ceramic fragment in question can be attributed to the group of golden reflections pottery of Spanish origin, most likely from Manises, an archaeometric position that adds different analysis techniques will allow us to understand all the complexity that this type of material involves in its production, we may or may not confirm its origin. The central idea is then that after a preliminary typological analysis can be made a technological analysis aimed at the reconstruction of the necessary procedures for the production of the type of object observed to avoid attributing the type of golden reflections pottery to, for example, other types of gilded ceramics that, independently of the type of glaze, staniferous or leaden, have been achieved by means of mono or bi coking. In fact, when one speaks of golden reflections pottery, of the type that was produced in Manises and that was commercialized by the port of Valencia towards the 18th century, port from which products arrived to the City of Buenos Aires, there is talk of a cooking (the ceramic, the enamel and the golden reflections) but which, according to Coll Conesa, could be achieved in three different ways: "Gold, technically called metallic reflection (barīq al-madenī), originates in the transformation of copper oxide (green) to metallic copper (red). To colour and alter its colour and optical properties are added to the pigment other metals, including silver or gold. In its production we must distinguish two basic techniques. On the one hand, the reduction of a glaze or enamel containing metallic oxides capable of being transformed to the metal state through reducing gases during a combustion process. On the other hand, obeying a different principle by depositing it on a glaze of thin iridescent metallic layer of little thickness, will also in reducing atmosphere. The first procedure was used in China already in the s. XI in reducing atmosphere. The first procedure was used in China already in the s. XI to obtain the sang de boeuf or rouge flambé, and was to add copper to a glaze and then cook it in reduction. It is a technique that was preserved in the Middle East, rediscovered in Europe in the s. XVIII and reproduced on lead glazes as usual in Seville from the late s. XIX In a lead glaze requires, at least, a temperature of about $850^{\circ} \mathrm{C}$, which may be higher depending on its formulation, so that the reducing gases alter the own glaze to reduce the copper metal contained in it. Muslim slabs have been found with lead and copper green glazes that accidentally show localized spots of red colour, due to lack of control of the combustion as a result of the partial reduction of the glaze. It is also possible to apply an enamel and after a first oxidation firing, a reduction is produced at a lower temperature that alters only this and not the support glaze, a technique widely used by potters to obtain a great variety of reflections of different colours, practiced by Caiger Smith and for the Serra saga in his Cornellà workshop. However, this was not the usual procedure for the Andalusian and Mudejar medieval gilded earthenware.

The second procedure, the deposition of a thin metal film nanostructured in reduction, is already documented in s. IX in Samarra. This is similar to the technique described by Abu'l-Qasim among those used in Kashan, with ingredients and procedures very similar to those traditionally known in the West, as we see in the comments of Enrique Cock in reference to Muel, forms of Alcora from the s. XVIII, the report of Martinez de Irujo of 1785 and compilations of Manises of s. XIX and XX. Abu'l-Qasim comments that $4.5 \mathrm{kgr}$ of orpiment (arsenic trisulfide), $3 \mathrm{kgr}$ of marcasite (iron sulphide), $1.5 \mathrm{kgr}$ of alumina, and $250 \mathrm{~g}$ of calcined copper are required, which are ground during twenty-four hours. $250 \mathrm{~g}$ of this mixture are mixed with 6 dirhams of silver and heated and ground four to eight hours, adding vinegar. With this you can already decorate and then cook, in third cooking, for seventy-two hours at moderate temperature. It also describes the technique of glaze reduction, by which the second firing reflex is achieved with significant savings.

The technique of the gilded earthenware documented by ethnography is transmitted to us by M. González Martí. This author says that in the metallic reflection the pigments have to carry copper oxide "to which other oxides are added, so that they lend scales of chromatic tones, according to the proportion of the measurements, and a medium that takes him in suspension". In fact, José Gestoso recalled that this had been recognized by Davillier, who claimed that the reflection was a copper protoxide silicate. He also mentions that Riocreux and Carrand confirmed that it contained silver and that the different colorations were based in part on the presence of different proportions of copper and silver, the reddish ones the first ones and the yellowish ones the latter, and also the action of the fire. Recent studies carried out with very precise analytical techniques have confirmed these results and rigorously explained the processes of formation of the decoration of the monochrome or polychrome shines that characterizes the first abasid productions"

In addition, according to that author: "The composition of the metallic reflection pigment used in Valencia until a few years ago involved copper oxide, Almazarrón's almagre (iron oxide), silver oxide and mercury or vermilion sulfide. First the copper $(\mathrm{Cu})$ and the silver (Ag) were cooked with sulfur, forming sulphides, to which was added the almazarrón and the vermilion. After a long grinding and refining, the mixture was burned, leaving the metals in an oxide state and releasing the lime and magnesium carbonates that accompany them. After a new refining it was emulsified with vinegar for its application, being usual to paint with a bird's feather. To produce reflection, it must then be cooked in a reducing atmosphere at a temperature that varies according to the melting point of the base glaze on which it is applied - always something below so that the reduction gases do not affect it-, between $550^{\circ} \mathrm{C}$ and $650^{\circ} \mathrm{C}$. This traditional reflex is achieved in the third cooking and is therefore critical, since much previous work is at stake. To control the result as much as possible, the type of furnace used and the combustion process is very important, which must be reducer and well prescribed". ${ }^{18}$

Starting from a historical and typological-normative analysis that allows us to distinguish large types of golden ceramics, as well as possible periods, it is then necessary to analyze this type of ceramic material also from the perspective of the materials, using the appropriate techniques for micro-morphological and physicochemical characterization, both from a structural point of view, as regards the components of the pasta or ceramic and, above all, of each of its surface finishing layers. Finally, in conjunction with its historical study, it is the set of all these analyzes that allows us to approximate the possible origin of ceramic materials, as well as their probable function and effective use. 


\section{Presentation of the case and analyzes carried out}

According to its formal and decorative aspects, observed with a naked eye, the sample or fragment whose analysis is presented here was cataloged as a fragment of golden reflections pottery (Figure 4). Likewise and after comparing it with complete pieces of this type by visualizing them in digital collections, it can be said that this fragment could have been part of a piece of ceramics used to bless, characteristic of the eighteenth century, since it presents a molding of floral motifs very similar to the case of the crown type of the pieces of ceramics used to bless that correspond to the inventory numbers: CE1/03082 and CE1/03083 of the digital collection of the National Museum of Ceramics and Sumptuary Arts González Martí and that are catalogued as coming from Manises.

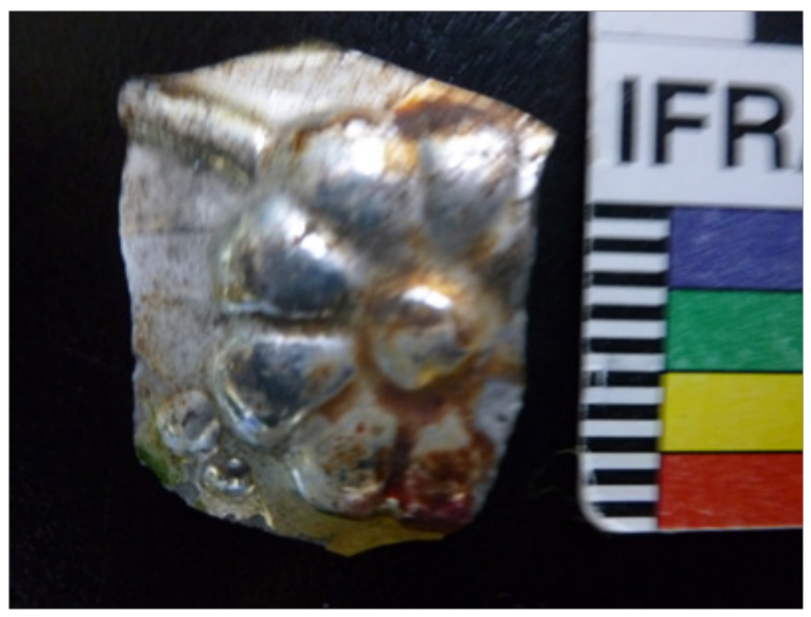

Figure 4 Fragment recovered in the site SVI, San Vicente, Province of Buenos Aires, Argentina.

However, in order to increase the scarce or nonexistent knowledge of this type of materials in our country, we proceeded to analyze this fragment from a more complete perspective for which, at the time of performing a dry mechanical cleaning (soft brushstroke) of the fragment, label it and perform its usual measurements, the next combinatorial of techniques was carried out. First of all, the sample was observed by means of a magnifying glass (10 to $80 \mathrm{X})$ Arcano brand ZTX 1:4 model, equipped with a digital camera Motic model Moticom 352 (LTO) and by means of a USB Optical Microscope (20 to $800 \mathrm{X}$ ) whose photographic records were made directly with the laptop from the related software Microcapture (MUSB). Secondly, and in specialized laboratories, the sample was observed using an Olympus Lext 3D Measuring Laser Microscope OLS 4000 (MC) Confocal Microscope and by an Electronic Scanning Microscope brand Zeiss iigma FEG equipped with an Energy Dispersive X-ray Spectrometer brand Oxford X-Max SSD 80mm (MEB-EDS).

\section{Results and final reflections}

The analysis of historical ceramic materials, supposedly imported and, therefore, apparently easily identifiable by their morphology and/ or decoration in their production processes, needs to be approached from a broad analytical perspective that overcomes traditional classifications. This tendency has become essential not only in the migratory contexts like the Argentina one but, also, in the supposed regions where the history indicates the production contexts. This becomes increasingly evident in, for example, the cases of review of the origin of earthenware identified as Spanish Talavera in front of the production of this type of earthenware in Puebla, México. In fact, it has not yet been possible to demonstrate, objectively, where and in what centres Talavera ceramics has been produced in Europe.

In this case, and through the combination of several techniques, we have observed that, in fact, and as described by the bibliography, it would be a fragment that has all the technological characteristics to classify it as golden reflections pottery. In addition, and in according to our contextual analysis, we can assume that this ceramic fragment would have been part of some of the typical pieces of the $18^{\text {th }}$ century, not only because of the type of decoration molded but also because it coincides with the period in which the pieces were reached golden reddish as in this case. Then, this fragment of ceramic could coincide by its type and decoration molded with a piece of ceramics used to bless, of the type that used to be placed in the entrances of houses and bedrooms (domestic context) or in churches and cemeteries (context ritual or religious). Then, not only the type and the possible shape have been corroborated, although perhaps it could also have been part of a decorative plate also usual in such ritual-religious-decorative contexts. The meticulous observation and with low power optical microscopy has made it clear that said floral motifs were achieved by molding. On the other hand, and with higher magnification techniques, the characteristic surface finish of this type of ceramic has been confirmed since it has been observed by Confocal Microscopy, a minimal but visible inter phase between the ceramic and the first surface finishing layer (enamel), as well as the difference with the final golden layer, that is, was clearly observed the three times of cooking. Through MEB-EDS, we have also detected Tin (Sn) in the enamel layer and a significant amount of Sulfur (S) in the surface which could explain the characteristic golden reflections finish. This characterization was complemented by an observation by means of Raman microspectroscopy, a technique by which blue (Copper phthalocyanine) was detected (Reinoso, com.pers.).

Although this physical-chemical characterization is preliminary because, as we have already pointed out in more detail in the description of the combinatorial of these types of analysis, ${ }^{19}$ it is a qualitative characterization (standarless), it coincides in general terms with technology traditionally described in the literature for the production of this type of pottery in Europe. For all this, in this work we emphasize the need to be intelligent users of the team to be able to direct the analysis carried out by the technicians. For this it is necessary to guide the search of those physical-chemical characteristics that may be indicate the particularities of a ceramic type, its production process, as well as a better data acquisition of the object that represents that ceramic , always scarce or, as in this only case. Likewise, we insist that all these precautions, without a doub, are the ones that will result in the best interpretations of the data.

\section{Acknowledgements}

To the former Secretary of Culture, Mr. Javier Carbone, who facilitated the start and continuity of this study project in the San Vicente Party, To the National Council of Scientific and Technical Research (CONICET) the PIP 660 grant (2012-2015) to solve field work and some analysis, To the National Microscopy System, for granting me two scholarships to continue my specialization in archaeometry. 


\section{Copyright}

The images are all of my authorship and free to use.

\section{Conflict of interest}

Author declares that there is no conflict of interest.

\section{References}

1. AGI. Pares, Portal of Spanish Archives. MP-Buenos Aires: General Archive of the Indies; $1788.164 \mathrm{p}$.

2. Angelo DJV. The conurbation of Buenos Aires. Argentina sum of Geography. Argentina: Buenos Aires; 1963:105-112.

3. Ottonello H. The original trace of Buenos Aires. Argentina sum of Geography. Argentina: Peuser, Buenos Aires; 1963:3-70.

4. De Paula A. The Buenosairean region and its urban process (1580 1779). Critical Seminar of the Institute of American Art and Aesthetic Research. 1993. 43 p.

5. Epifanio H. San Vicente, a town, a party (1780-1928). Argentina: Municipal Intendance of San Vicente, Buenos Aires; 2001.

6. López MA, Torres Núñez MM, Vommaro MN. The ranchers in San Vicente from the mid-nineteenth century to the early twentieth century. In: Landa Carlos, Virginia Pineau, Emanuel Montanari, Jimena Doval, editors. Landscapes of the Pampean campaign (XIX and XX centuries). Approaches from rural archeology in Argentina. South American Archaeology Series. 2018;32:73-112.

7. Barral ME. Rural parishes, clergy and population in Buenos Aires during the first half of the nineteenth century. Yearbook IEHS. 2005:359-388.

8. Barral ME, Fradkin RO. The towns and the construction of the structures of institutional power in the Buenos Aires campaign (1785-1836). Bulletin of the Institute of Argentina and American History Dr. E Ravignani, Third Series. 2005;27:7-48.
9. Official Registry of the Province of Buenos Aires. Books I and II. Buenos Aires: Álvarez Editorial; p. 1821-1822.

10. Fradkin RO, Canedo M, Mateo J. Land, population and social relations in the Buenos Aires campaign (18th and 19th centuries). Argentina: GIHRR/ UNMDP, Mar del Plata; 1999.

11. Fradkin RO, Garavaglia JC. In search of a lost time. The economy of Buenos Aires in "the country of abundance, 1750-1865. Argentina: Prometeo, Buenos Aires; 2005.

12. BNA. National Library Argentina, MA009867-PART 3. Maps Department of Engineers; 1890.

13. Schávelzon D. Catalog of historical ceramics of Buenos Aires (XVI-XX centuries). With notes on the Rio de La Plata región CD, Argentina: EVM, Buenos Aires; 2001.

14. Dictionary of ceramic materials. Subdirectorate General of Museums, Ministry of Education, Culture and Sports. Technical General Secretariat. Spain: Publications Center, Madrid; 2000.

15. Seseña N. Popular ceramics shop. Coarse ceramics in Spain. Spain: Alianza Editorial, Madrid; 1997

16. Fatás Cabeza G, GM Borrás. Dictionary of Art terms and elements of archaeology, heraldry and numismatics. Spain: Alianza Editorial, Madrid; 2008.

17. Vendrell M, Roqué J, Pérez Arantegui J, et al. The golden reflections ceramics: a technical approach to medieval nanotechnology. Proceedings of the International Congress European Network of Islamic Art Museums. 2012:437-450.

18. Consea CJ. Technique, classroom and social distinction in medieval ceramics. Annals of Art History. 2014;24:69-97.

19. López MA. The combined use of Optical Microscopy, Confocal Microscopy and Scanning Electron Microscopy with Energy Dispersive $\mathrm{X}$-ray Spectrometer for the analysis of historical ceramic materials. World of Before. 2015;9:99-120. 